\title{
POR QUÉ OCURRIÓ UNA GUERRA CIVIL EN EL SALVADOR Y NO EN HONDURAS*
}

\author{
Rafael Antonio Pleitez ${ }^{* *}$
}

$\mathrm{E}$

n general, El Salvador y Honduras comparten similares pro blemas de pobreza, desigualdad y una tradición autoritaria; sin embargo, en El Salvador se dieron fuertes presiones revolucionarias (Ruhl 1984:3). La pregunta es por qué ocurrió una guerra civil en El Salvador mientras Honduras permaneció con relativa estabilidad política.

En la literatura sobre revoluciones e insurrecciones, encontramos teorías que pueden ayudar a explicarnos los diferentes resultados históricos en Honduras y El Salvador a pesar de las condiciones estructurales similares tal como la estructura agraria. En las teorías principales de la revolución, se pueden distinguir dos grupos: primero, teorías que identifican una fuerza principal que puede causar una revolución como la desigualdad en la distribución de la tierra y/o los ingresos; segundo, teorías que identifican un grupo social que es el principal protagonista en las revoluciones o

- Traducción del artículo "why a civil war occurred in El Salvador, but not in Honduras". Presentado al Centro de Estudios Latinoamericanos de la Univesidad de Pittsburgh.

** Profesor investigador del Departamento de Economía de la UCA. 
insurrecciones, como los campesinos o algunas élites. Nosotros sostenemos que existe un enlace importante entre los dos grupos de teorías, es decir, cómo las élites responden a retos sociales importantes como por ejemplo una creciente desigualdad en la distribución de la tierra (Pleitez 1993:1-3).

Al menos, desde la época de Aristóteles, la desigualdad ha sido vista como la principal causa de rebelión y revolución. La explicación de Aristóteles sobre la conexión entre desigualdad y revolución destaca un elemento subjetivo: es importante cómo la gente concibe y siente la realidad de la desigualdad.

Muchos autores han pensado que la mala distribución de la tierra es la clave determinante para una revolución y la inestabilidad social. De acuerdo con Prosterman y Reidinger (1987), el desposeimiento de tierra ha sido el principal determinante de graves desórdenes sociales en el presente siglo. Sin embargo, Muller y Seligson (1987) utilizando una regresión a través de varios países encontraron que el desposeimiento de tierra se vuelve una variable irrelevante cuando la desigualdad en la distribución de los ingresos se toma en cuenta (p. 436). Los autores concluyen que la desigualdad en la distribución de la tierra es relevante para la violencia política "sólo en la medida que esté asociada con la desigualdad de la distribución nacional del ingreso (p. 443).

A pesar de los hallazgos de Muller y Seligson, preferimos tomar la desigualdad de la distribución de la tierra como la variable clave para la desigualdad objetiva en El Salvador y Honduras, con base en las siguientes razones:

(1) La relevancia del sector agrícola en sus economías durante las décadas de 1960 y 1970. La contribución del sector agrícola al producto nacional bruto, exportaciones y porcentajes de la fuerza laboral que trabaja en este sector son indicadores de la relevancia del agro (ver cuadro 1).

(2) La guerrilla salvadoreña tenía su base en combatientes campesinos. El problema crítico para los campesinos, es la distribución de la tierra.

(3) La tierra ha sido la fuente principal de riqueza para las oligarquías nacionales en estos países. Por ejemplo, Paige (1987) en- 
contró que la élite cafetalera salvadoreña domina la oligarquía salvadoreña "con aproximadamente dos tercios de las fortunas de sus familias basadas en la riqueza proveniente del café" (p. 183).

\section{Cuadro 1}

El peso del sector agrícola en las economías de El Salvador y Honduras (1960-1980) ${ }^{1}$

\begin{tabular}{llllll}
\hline 1960 & 1965 & 1970 & 1975 & 1980 \\
\hline
\end{tabular}

\section{El Salvador}

$\%$ del Producto

Nacional Bruto

$\begin{array}{lllll}30.8 & 26.9 & 26.2 & 25.2 & 25.6\end{array}$

$\%$ de Exportaciones

95.2

$84.7 \quad 70.6$

70.4

72.3

$\%$ de Empleo

60.6

53.7

51.2

48.0

35.0

\section{Honduras}

$\%$ del Producto

Nacional Bruto

$\%$ de Exportaciones

32.8

36.3

36.4

29.2

28.7

$\%$ de Empleo

n.d

n.d

76.2

69.9

75.0

$\begin{array}{lllll}66.7 & 70.3 & 61.0 & 59.9 & 56.4\end{array}$

(4) En ambos países, la tierra se ha vuelto más escasa para los pequeños agricultores debido a la expansión de la agricultura de exportación y al crecimiento de la población en este siglo. Entonces, la distribución de la tierra se ha vuelto parecida a las características del juego "suma-cero" entre los campesinos y los propietarios. Esto es claramente una fuente de conflicto social.

Midlarsky $(1982,1988)$ argumenta que una causa principal de violencia política en las sociedades agrarias es un proceso de bifurcación en el patrón de la tenencia de la tierra. Esto es, dada una cantidad fija de tierra en combinación con factores tales como un alto crecimiento de población y la expansión de la agricultura de exportación, la extensión promedio de las propiedades de los pequeños agricultores se va a reducir. Si las grandes haciendas permanecen relativamente intactas, tenemos una situación en la que los ricos permanecen ricos y 
el pobre se vuelve más pobre (Muller-Seligson-Fu 1989: 578).

Con el fin de mejorar el poder explicativo de la desigualdad como la principal causa de rebeliones y revoluciones, se ofrecen tres sugerencias específicas: (1) de acuerdo con Sigelman y Simpson (1977), un modelo explicativo adecuado de la relación desigualdad-violencia debería incluir estimados subjetivos de la desigualdad; (2) el contexto político (por ejemplo, tipos de regímenes o estructura estatal) debería incluirse (Brockett 1992:176; Muller y Seligson 1987:429; Midlarsky y Roberts 1985; 17; Skocpol 1981:373; Moore 1966:457); y (3) de acuerdo con Brockett (1992), la dimensión temporal de la relación entre desigualdad de la distribución de la tierra y la violencia política de masas debe ser estudiada (p. 175).

\section{Discusión de las hipótesis}

Tna de las explicaciones más comunes para la relativa estabilidad política de Honduras es que la tierra está distribuida con menos desigualdad que en los países vecinos (Morris 1981:38; Reina 1981:30; Rosenberg 1980:19-20; González 1978: 597-598; Stokes 1966:22).

Mark Ruhl (1984) encontró que El Salvador y Honduras encajan en el patrón estándar latifundio-minifundio de desigualdad rural (p. 57). Sin embargo, Ruhl encontró diferencias importantes entre las estructuras agrarias de estos países (pp. 42 y 57):

(1) Sólo $17 \%$ de las fincas en Honduras están clasificadas como "microfincas" (menos de una hectárea), pero cerca de la mitad de todas las fincas salvadoreñas lo son.

(2) Dos tercios de las fincas de Honduras eran poseídas bajo formas "seguras" de tenencias de la tierra (34\% propietarios y $33 \%$ alquiladas a tarifas muy bajas) y sólo el $40 \%$ de los agricultores salvadoreños eran dueños de sus propias tierras.

(3) Una mayor proporción de fincas de tamaño mediano (5-50 hectáreas) en Honduras ( $32 \%$ de todas las fincas en Honduras versus $12 \%$ de todas las fincas en El Salvador).

(4) La existencia de una reforma agraria en Honduras desde 1962 que ha distribuido 207,433 $\mathrm{Ha}$. de tierra a 46,890 familias rurales hasta 1979. 
Ruhl argumentó que el descontento político de los campesinos es menor en Honduras que en El Salvador debido a estas diferencias en las estructuras agrarias. Además, en Honduras se permitió que los campesinos se organizaran. En El Salvador, las organizaciones campesinas fueron reprimidas violentamente y la reforma agraria fue bloqueada por la oligarquía rural (Ruhl 1984:58).

Sin embargo, podemos preguntarnos: ¿Son suficientes estas diferencias en las estructuras agrarias para explicar por qué un número importante de campesinos se volvieron revolucionarios en El Salvador y no así en Honduras?

De acuerdo con Moore (1976: 308), las condiciones materiales no son el factor decisivo para provocar una insurrección o una revolución aunque ciertamente contribuye a provocarlas.

Una pregunta clave es: ¿Qué hace a los campesinos insurrectos o revolucionarios? Los académicos han enfatizado en diferentes grados el papel de las cuatro condiciones que contribuyen a un campesinado revolucionario: solidaridad, autonomía, movilización y daño a la economía campesina..

Wickham-Crowley (1991) define estas condiciones. La autonomía del campesinado existe cuando "las acciones campesinas no están sujetas a un escrutinio y control cercano por parte de representantes de las élites económicas o políticas". (p. 176). La solidaridad campesina existe cuando "la vida diaria de los cultivadores proporciona situaciones recurrentes para decisiones colectivas y acciones colectivas que gobiernan las vidas de ellos" (p. 177). La movilización es el proceso en el cual "los campesinos vienen a comprometer sus recursos (tierra, alimento, tiempo, energía, y aún sus vidas) con las organizaciones revolucionarias" (p. 177). Finalmente, podemos hablar de daño: (1) "cuando los campesinos mismos perciben que su acceso a las necesidades de subsistencia básica está fundamentalmente amenazado; o (2) cuando la evidencia "macroeconómica" indica fuertemente tipos de daño similares a las pocas posibilidades de subsistencia (precios de las cosechas que disminuyen, pérdida de tierra en las plantaciones, etc.)" (p. 178).

Las diferencias que Ruhl encontró en las estructuras agrarias de El Salvador y Honduras pueden ser vistas como indicadores "macro-económicas" del daño a la economía de los campesinos en 
estos países. Con base en la experiencia de los movimientos revolucionarios de Nicaragua y El Salvador, argumentamos que el papel de la Iglesia Católica fue significativo para crear solidaridad entre los campesinos así como entre campesinos y otros grupos sociales tales como obreros e intelectuales. El tipo de ideas religiosas entre los campesinos puede también facilitar o impedir su movilización política.

Otros factores que justifican incluir el papel de la religión en el proceso de convertir a los campesinos en revolucionarios son: (1) La religión tiene un lugar importante en la vida de los campesinos. El catolicismo tradicional en Honduras y El Salvador han contribuido a la cosmología del campesino que confirió legitimidad al papel de las clases gobernantes y acentuó la resignación (ser pasivos) y la aceptación de un destino individual. Moore (1966) argumentó que esta cosmología "podría servir. concebiblemente como un fuerte impedimento para la insurrección o rebelión si los campesinos aceptaran sus normas" (p. 455); (2) En la década de 1960 y 1970, un "sector profético" de la Iglesia Católica jugó un rol importante al explicar la complejidad social de las dificultades económicas del campesinado. Además, la realidad de la pobreza y la desigualdad fue entendida por ese sector como un pecado social contrario a la voluntad de Dios. La misión de la Iglesia fue comprendida como la construcción de una nueva sociedad de acuerdo con la voluntad de Dios. Los campesinos fueron organizados como parte de un proyecto "revolucionario": "La construcción histórica del Reino de Dios". Los dirigentes revolucionarios que provenían de organizaciones político/militares tomaron ventaja del trabajo de la Iglesia al elevar la conciencia social de los campesinos.

Con el propósito de estimar el nivel de desigualdad subjetiva y para incluir el papel esencial de las ideas de la Iglesia Católica en el proceso para hacer revolucionarios a los campesinos, hemos creado la categoría de "Conciencia de Injusticia Social" (CIS). Con el fin de poder hablar acerca de grados de conciencia de injusticia social, hemos identificado cuatro "etapas" principales para elevar la conciencia de injusticia social. La primera etapa es cuando una persona reconoce su realidad social como injusta. En la segunda etapa, la persona conoce las causas estructurales que generan su situación social injusta. La tercera etapa es cuando la persona percibe que su 
vida está bajo riesgo debido a represión política aún si no está políticamente organizada. En la etapa final, la persona cree que no es posible cambiar el status quo a través de los canales institucionales.

Consideramos que tres elementos principales pueden explicar los grados diferentes de "CIS" entre Honduras y El Salvador: (1) la fuerza de la iglesia cristiana abogando por un cambio social, (2) los niveles de represión política y (3) el nivel de desigualdad, específicamente la desigualdad en la distribución de la tierra. Estimamos que el grado de conciencia de injusticia social (CIS) es más alto entre los campesinos salvadoreños que entre los hondureños. El grado de CIS contribuye significativamente a hacer revolucionarios a los campesinos.

Con el propósito de incluir el contexto político, utilizaremos los tipos de estructura estatal definidos por Midlarsky y Roberts (1985), los tipos son: (1) estado instrumentalista, es decir, el estado es esencialmente un instrumento de dominio de clases. "El estado reglamenta en el interés de la clase dominante y a menudo a través de las personas de la clase dominante" (p. 18) o a través del poder coercitivo de la institución militar. El estado protege los privilegios de la clase dominante y suprime cualquier amenaza de la clase más baja al sistema de jerarquía de clase o al proceso de acumulación (p. 19); (2) estado institucional autónomo, el cual "ejerce una medida significativa de autonomía de la clase dominante y otras fuerzas sociales y persigue los intereses del estado que se pueden distinguir de aquellọs de la clase dominante" (p. 20); y, (3) estado autónomo personalista, es presidido por un dirigente único de tipo caudillista. "El líder máximo generalmente dirige en forma conjunta con el establecimiento militar, el cual está bajo su control directo y con la complicidad de la clase dominante (p. 20). Los autores argumentan que los tipos de estructuras estatales tienden a perpetuar estructuras de desigualdad y estratificación de clase. Entonces, son vulnerables a las presiones de redistribución desde abajo. Sin embargo, los estados personalistas son los más vulnerables debido a sus formas transparentes de dominación y de desigualdad seguidos por los estados instrumentalistas y los estados autónomos, respectivamente, en el grado de vulnerabilidad, (p. 21-24).

En consecuencia, la combinación de alta desigualdad de la distribución de tierras en un contexto de escasez de tierras, el alto grado de 
conciencia de injusticia social, y la existencia de un estado personalista o instrumentalista son las condiciones que crean un fuerte movimiento revolucionario basado en la participación campesina. Esperamos encontrar diferencias importantes en estas condiciones entre El Salvador y Honduras durante las décadas de 1960 y 1970.

\section{Metodología}

1 roponemos crear un "Indice de Inestabilidad Social" que sea igual al "Indice de Desigualdad" más el valor de rango de la estructura estatal (IIS = ID + EE). El rango para el "Indice de Inestabilidad Social" es de uno a seis puntos. Esperamos que los valores de 5 a 6 puntos reflejen una situación de revolución social; 4 a 4.99 puntos, reflejen una situación social cercana a una guerra civil o intentos frecuentes de rebelión; 3 a 3.99 puntos, reflejen una situación social en la cual existe un rápido proceso de formación de movimientos insurrecionales o revolucionarios; y de 1 a 2.99 puntos, reflejen una estabilidad política relativa. El "Indice de Inestabilidad Social" se estima para cada país en las décadas de 1960 y 1970.

(A) El Indice de Desigualdad tiene dos componentes:

(1) La desigualdad objetiva se mide por el Indice de Bifurcación en la desigual distribución de tierras. El coeficiente de bifurcación de tierras es la relación del número promedio de hectáreas de las grandes propiedades por el número promedio de hectáreas de las pequeñas propiedades. Este coeficiente se multiplica por la proporción de propiedades pequeñas en el país la cual es el Indice de Desigualdad en la Distribución Bifurcada de Tierras (MullerSeligson-Fu 1989:581). La propiedades que son menores de cinco hectáreas se definen como pequeñas propiedades y las propiedades que tienen más de cien hectáreas, como grandes propiedades. La información está basada en el censo nacional agrícola de 1961 y de 1971 para El Salvador, y de 1966 y 1974 para Honduras.

Con el fin de determinar el valor de rango para Honduras y El Salvador, el promedio del índice de desigualdad bifurcada de tierras en América Latina se calcula para los años de las décadas de 1960 y 1970. El valor de rango de uno se asigna al promedio. Los valores de rango de Honduras y El Salvador se estiman proporcionalmente a ese promedio. 
(2) La desigualdad subjetiva será estimada por medio de la influencia que el pensamiento social de la Iglesia Católica ejerció al elevar la conciencia de injusticia social, especialmente la conciencia de los campesinos durante los años de las décadas de 1960 y 1970.

El valor de rango de la desigualdad subjetiva (Conciencia de Injusticia Social) es de cero a dos. El valor cero refleja una situación en la cual la Iglesia Católica evita establecer juicios éticos en relación con problemas políticos. Además, la tendencia de la Iglesia será asumir una posición política "neutral". Si la principal tendencia en la Iglesia es fomentar reformas sociales con el fin de facilitar el desarrollo social y económico en el sistema capitalista, se le asignará un valor de uno. Finalmente, a una iglesia profética que fomenta un cambio social radical - "nuevo cielo y nueva tierra"- se le asignará un valor de dos. Por supuesto, encontramos una mezcla de estas posiciones dentro de la Iglesia Católica. Con base en la historia de la Iglesia Católica en estos países para el período 1960-1980, se determinará la importancia relativa de cada tendencia.

(B) El valor de rango de la estructura del estado. Midlarsky y Roberts (1985) definieron tres tipos de estructuras estatales, la personalista autónoma, la instrumentalista y la institucional autónoma. Los tres tipos de estructura estatal podrían ser medidos por una escala de orden de rango de tres puntos. Mientras más alto el valor de rango, habrá mayor posibilidad de altos niveles de violencia política. Como consecuencia, el "valor de rango" de un estado personalista autónomo es tres, el del estado instrumentalista es de dos y el del estado institucional autónomo es uno.

Los valores de rango de El Salvador y Honduras están estimados proporcionalmente al promedio del índice de desigualdad bifurcada en América Latina. Los valores para El Salvador son 1.06 en los años de la década de 1960 y de 0.93 para los de la década de 1970. Los valores para Honduras son 0.3 en los años de la década de 1960 y de 0.5 para los de 1970.

De acuerdo con este índice, El Salvador muestra patrones de bifurcación promedio de distribución de tierras dentro del contexto de América Latina. Honduras está entre los cinco países donde el índice es más bajo en los años de la década de 1960. Honduras muestra un patrón creciente de bifurcación de tierras entre 1966 y 
1974 mientras que El Salvador muestra una pequeña reducción en el patrón bifurcado de distribución de tierras entre 1961 y 1971.

\section{Resultados}

1. Desigualdad Objetiva: Indice de Bifurcación en la desigual Distribución de Tierra.

\section{Cuadro 2}

Desigualdad de la Distribución Bifurcada de Tierras en los países de América Latina

\begin{tabular}{|c|c|c|c|c|c|c|}
\hline \multirow[b]{2}{*}{ País } & \multicolumn{3}{|c|}{ Hectárea por finca } & \multirow{2}{*}{$\begin{array}{c}\text { Coeficiente de } \\
\text { Bifurcación } \\
\text { Tierras }\end{array}$} & \multirow{2}{*}{$\begin{array}{c}\text { Proporción de } \\
\text { Propiedades } \\
\text { Pequeñas }\end{array}$} & \multirow{2}{*}{$\begin{array}{c}\text { Indice de } \\
\text { Desigualdad } \\
\text { Bifurcada }\end{array}$} \\
\hline & Año & $\begin{array}{c}\text { pequeña } \\
\text { (<5) }\end{array}$ & $\begin{array}{l}\text { grande } \\
(>100)\end{array}$ & & & \\
\hline Argentina & 1960 & 2.8 & 895.0 & 319.6 & 0.16 & 51.1 \\
\hline Brasil & $\begin{array}{l}1960 \\
1970\end{array}$ & $\begin{array}{l}2.5 \\
2.2\end{array}$ & $\begin{array}{l}565.8 \\
498.9\end{array}$ & $\begin{array}{l}226.3 \\
226.8\end{array}$ & $\begin{array}{l}0.31 \\
0.37\end{array}$ & $\begin{array}{l}70.2 \\
83.9\end{array}$ \\
\hline Chile & 1965 & 1.7 & 1232.7 & 725.1 & 0.49 & 355.3 \\
\hline Colombia & $\begin{array}{l}1960 \\
1971\end{array}$ & $\begin{array}{l}1.6 \\
1.3\end{array}$ & $\begin{array}{l}419.6 \\
418.1\end{array}$ & $\begin{array}{l}262.3 \\
321.6\end{array}$ & $\begin{array}{r}0.63 \\
0.6\end{array}$ & $\begin{array}{r}165.2 \\
193\end{array}$ \\
\hline Costa Rica & $\begin{array}{l}1963 \\
1973\end{array}$ & $\begin{array}{l}2.1 \\
1.7\end{array}$ & $\begin{array}{l}463.6 \\
360.9\end{array}$ & $\begin{array}{l}220.8 \\
212.3\end{array}$ & $\begin{array}{l}0.39 \\
0.43\end{array}$ & $\begin{array}{l}86.1 \\
91.3\end{array}$ \\
\hline $\begin{array}{l}\text { República } \\
\text { Dominicana }\end{array}$ & $\begin{array}{l}1960 \\
1971\end{array}$ & $\begin{array}{l}1.2 \\
1.5\end{array}$ & $\begin{array}{l}513.3 \\
381.5\end{array}$ & $\begin{array}{l}427.8 \\
254.3\end{array}$ & $\begin{array}{l}0.86 \\
0.77\end{array}$ & $\begin{array}{l}367.9 \\
195.8\end{array}$ \\
\hline El Salvador & $\begin{array}{l}1961 \\
1971\end{array}$ & $\begin{array}{l}1.2 \\
1.2\end{array}$ & $\begin{array}{l}360.5 \\
330.1\end{array}$ & $\begin{array}{l}300.4 \\
275.1\end{array}$ & $\begin{array}{l}0.85 \\
0.74\end{array}$ & $\begin{array}{l}255.4 \\
203.6\end{array}$ \\
\hline Guaternala & 1964 & 1.8 & 354.8 & 197.1 & 0.87 & 171.5 \\
\hline Honduras & $\begin{array}{l}1966 \\
1974\end{array}$ & $\begin{array}{l}2.5 \\
1.9\end{array}$ & $\begin{array}{l}262.5 \\
331.1\end{array}$ & $\begin{array}{r}105 \\
174.3\end{array}$ & $\begin{array}{l}0.68 \\
0.64\end{array}$ & $\begin{array}{r}71.4 \\
111.6\end{array}$ \\
\hline México & $\begin{array}{l}1960 \\
1970\end{array}$ & $\begin{array}{l}1.5 \\
1.7\end{array}$ & $\begin{array}{l}1439.2 \\
1331.8\end{array}$ & $\begin{array}{l}959.5 \\
783.4\end{array}$ & $\begin{array}{l}0.66 \\
0.51\end{array}$ & $\begin{array}{l}633.3 \\
399.5\end{array}$ \\
\hline Nicaragua & 1963 & 2.6 & 245.6 & 94.5 & 0.51 & 48.2 \\
\hline Panamá & $\begin{array}{l}1960 \\
1971\end{array}$ & $\begin{array}{l}2.2 \\
1.4\end{array}$ & $\begin{array}{l}262.4 \\
293.9\end{array}$ & $\begin{array}{l}119.3 \\
209.9\end{array}$ & $\begin{array}{l}0.46 \\
0.47\end{array}$ & $\begin{array}{l}54.9 \\
98.7\end{array}$ \\
\hline Perú & $\begin{array}{l}1961 \\
1972\end{array}$ & $\begin{array}{l}1.5 \\
1.5\end{array}$ & $\begin{array}{l}1484.4 \\
1184.4 \\
\end{array}$ & $\begin{array}{l}989.6 \\
789.6 \\
\end{array}$ & $\begin{array}{l}0.81 \\
0.76 \\
\end{array}$ & $\begin{array}{l}801.6 \\
600.1 \\
\end{array}$ \\
\hline $\begin{array}{l}\text { América } \\
\text { Latina } \\
\text { (promedio) }\end{array}$ & $\begin{array}{l}1960 \mathrm{~s} \\
1970 \mathrm{~s}\end{array}$ & & & & & $\begin{array}{l}240.9 \\
219.7\end{array}$ \\
\hline
\end{tabular}

Tomado de: Muller-Seligson-Fu, 1989, p. 582. 
2. Desigualdad subjetiva: El rol de la Iglesia Católica en cuanto a elevar la conciencia social

\subsection{El pensamiento social de la Iglesia Católica hondureña 1960- 1980.}

En los últimos años de la década de 1950, la Iglesia en Honduras se caracterizaba por un clero muy pequeño y una población distribuida en un vasto territorio. En consecuencia, el trabajo misionero era el desafío principal para esta Iglesia. Con el fin de hacerlo, los religiosos extranjeros y los laicos se integraron en la misión. El objetivo principal era llevar el ministerio a la población rural. Se pueden identificar tres modelos principales de iglesia:

\section{(A) La iglesia institucional}

Este sector de la iglesia se identifica como la iglesia "oficial", la cual es parte del status quo. En consecuencia, este sector de la Iglesia no puede permitir una crítica radical del status quo. La iglesia institucional rechaza el interrumpir el orden social. La negociación de intereses, el consenso, la integración social son las actitudes sociales que este sector de la Iglesia generalmente fomenta.

(B) La Iglesia del Desarrollo

La iglesia fue influenciada por teorías del desarrollo económico. Algunos sacerdotes generaron teorías tales como la teoría del desarrollo integral del Padre Lebret. Esta perspectiva de desarrollo sostiene que la gente se beneficia por el desarrollo económico y social por medio de la organización popular. El progreso técnico fue entendido como el motor para el desarrollo dentro del sistema capitalista.

El juicio ético sobre la realidad social es que un sistema capitalista "despótico" que genera pobreza masiva y altos niveles de desigualdad es un orden social en contra de la voluntad de Dios.

(C) La Iglesia Profética

Podemos entender este sector de la Iglesia como un extremo crítico de la iglesia del desarrollo. Este modelo de la iglesia tiende a aparecer en un contexto social caracterizado por una opresión y explotación profunda. Esta realidad abre la posibilidad no sólo 
para un juicio ético de que esta realidad es contraria a la voluntad de Dios sino también para mostrar una nueva alternativa de dirección.

Un objetivo importante de este modelo de iglesia es elevar la conciencia entre los grupos sociales, por ejemplo los campesinos. Dos objetivos principales son crear un sentido de comunidad cristiana y promover una responsabilidad común en el trabajo de la Iglesia. En los años de la década de 1960, la iglesia "oficial" promovió una rápida expansión de la enseñanza espiritual y social de la Iglesia a la población rural en Honduras. Esto promovió la participación laica con especial énfasis en las poblaciones campesinas. Este enfoque dominante fue tomado por el "modelo de desarrollo de la iglesia". En los últimos años de la década de 1960, la iglesia profética aumentó su importancia a través de su misión de evangelizar la población rural (Beanco y Valdeverde 1987: 221224). En una forma general, los obispos habían apoyado la reforma agraria. Pero "existía temor entre los líderes de la Iglesia de que si la Iglesia continuaba estando asociada con la organizaciones campesinas que están promoviendo directamente la ocupación de tierras, la amenaza de represiones contra sacerdotes y la deportación masiva del clero sería ejecutada" (White R. 1977: 296). El caso de la iglesia profética en la Diócesis de Olancho es esencial para comprender los cambios en la Iglesia Católica de Honduras en 1975. El contexto social de Olancho está caracterizado por una creciente concentración de tierra a través de la expansión de latifundios de ganado. Además, los terratenientes a través de guardias personales y alianzas con soldados, ejercitan el dominio político de esta región. Muchos campesinos que habían participado en cursos bíblicos y de doctrina social se unieron a organizaciones campesinas tales como la Unión Nacional de Campesinos UNC (Blanco y Valverde 1987: 92). Estos campesinos se involucraron en una confrontación directa con los terratenientes, principalmente por medio de "tomas de tierra".

El 25 de junio de 1975, quince personas incluyendo un sacerdote fueron asesinados por el ejército. Esto fue seguido por una persecución de la Iglesia Católica en Olancho: el obispo, los sacerdotes, las monjas y los laicos. La primera reacción de la Iglesia Católica entera fue un rechazo abierto contra esta masacre y defender 
los principios cristianos de justicia social. Por ejemplo, en una carta pública, los obispos pidieron al gobierno una efectiva y rápida implementación de la reforma agraria (Blanco y Valverde, p. 138).

Sin embargo, la iglesia institucional fue cambiando del terror inicial a la actitud prudente de acción pastoral. Esto significó que abandonara el apoyo para un modelo de iglesia laica con un énfasis en las organizaciones campesinas. Dos razones principales que ayudan a explicar esa decisión son: (1) controlar las acciones pastorales con el fin de evitar una confrontación directa con el gobierno y tener una hegemonía de las decisiones principales en la iglesia con el fin de evitar una democratización dentro de la iglesia. La iglesia institucional decidió enfatizar una práctica religiosa personalista y espiritual sin ningún juicio ético acerca de problemas políticos. La "iglesia de desarrollo" mantuvo proyectos locales para ayudar a las necesidades específicas de la población pero sin juicio político. Desde 1976, el modelo institucional dominante ha sido efectivo para propagar un trabajo pastoral espiritual e individualista entre la población católica.

Basado en esta información, podemos identificar tres fases en el rol de la iglesia católica que influenciaron la conciencia social entre el pueblo hondureño:

(a) En los años de la década de 1960, la iglesia del modelo de desarrollo era dominante. La Iglesia fomentaba las reformas sociales. Un objetivo principal fue que la gente pobre tuviera acceso a la nueva tecnologia y servicios con el fin de modernizar el sistema capitalista en Honduras. En consecuencia, un valor de rango de uno puede ser asignado a este período.

(b) En los últimos años de la década de 1960 hasta mediados de la década de 1970, la iglesia profética tuvo más influencia en el trabajo de misiones. Este sector de la Iglesia fomentó cambios sociales radicales. En consecuencia, un valor de rango de dos se puede asignar a este período.

(c) Desde 1976, aproximadamente, el modelo "oficial" de iglesia ha sido el dominante. Este sector de la Iglesia ha promovido una forma individual y espiritual de vivir la fe cristiana sin hacer una referencia directa a la situación política. Consecuentemente, un valor de rango de cero se puede asignar a este período. 
(B) El pensamiento social en la Iglesia Católica salvadoreña 19601980.

Históricamente, la Diócesis de San Salvador ha tenido la mayor influencia pastoral, social y política en la Iglesia Católica salvadoreña ${ }^{3}$. Monseñor Chávez y González fue arzobispo de San Salvador desde 1938 hasta 1977. Apoyó una teología que fomentaba la participación de misioneros laicos en la vida política. Con base en la doctrina social de la Iglesia, estos laicos deberían trabajar para las reformas sociales en El Salvador.

En los años de la década de 1960, muchos grupos católicos, por ejemplo, Acción Católica estaban comprometidos a trabajar en programas de promoción humana. La idea fue organizar grupos alrededor de necesidades específicas. Por ejemplo, FECCAS4, una de las organizaciones campesinas más importantes en los años de la década de 1970, fue organizada por miembros católicos con el fin de fortalecer el poder de negociación de los campesinos para obtener precios más bajos de insumos. Los grupos católicos utilizaron la metodología de "ver, escuchar e interpretar" para su enseñanza acerca de la realidad social en El Salvador. El proyecto propuesto fue en general: La promoción de un "hombre nuevo" que busca justicia en la sociedad"s. Los campesinos y los pobres extremos en las ciudades fueron dos grupos objetivos. Pero un cambio social radical no fue promovido durante esta década. Con base en las características anteriores, un valor de rango de uno se puede asignar a este período.

Al principio de la década de 1970, algunos cristianos y marxistas comenzaron a aparecer quienes estaban comprometidos a desarrollar una estrategia militar con el fin de derrocar al gobierno y el status quo. Por ejemplo, algunos miembros de grupos católicos en las universidades crearon un grupo que no tenía un nombre formal pero que era conocido como "el movi" (el movimiento). Algunos miembros del movi tales como Janet Samour, Ana María Castillo, Felipe y Virginia Peña fueron altos miembros de las organizaciones revolucionarias político-militares (Henríquez 1988:213).

El documento de Medellín y la Teología de la Liberación tuvieron una influencia importante en el trabajo pastoral de la iglesia católica en la década de 1970. La iglesia profética enfatizó el rol de 
la historia de la salvación del pueblo de Israel como un ejemplo de que Dios ha ayudado a su pueblo en su proceso de liberación. Este proyecto de salvación fue convergiendo con el proyecto político histórico que las organizaciones revolucionarias estaban promoviendo. Las organizaciones populares eran el espacio en el cual estos proyectos se intersectaron. La participación popular ha tenido como un fin la transformación del status quo a través de un proceso de creación de poder popular. Este fin podría involucrar dos utopías: El Reino de Dios y el Socialismo. La iglesia profética alcanzó su nivel más alto de influencia no sólo en la Iglesia Católica sino también en todo el país, especialmente en las organizaciones populares entre 1977 y 1980. Monseñor Oscar Romero fue el líder vital para la iglesia profética y las organizaciones populares en ese período. Monseñor Romero apoyó las organizaciones populares como un derecho del pueblo de El Salvador en la búsqueda de soluciones para sus problemas. Monseñor Romero se convirtió en la voz más clara que denunció la injusticia social en El Salvador (Cardenal 1987: 13-31). Con base en las características anteriores, se puede asignar a este período un valor rango de dos.

\section{Tipos de estructura del estado}

\section{(A) Tipo de relaciones estado-clases en El Salvador}

De acuerdo con Midlarsky y Roberts (1985), el régimen militar en El Salvador es un claro ejemplo de un estado instrumentalista. En El Salvador, en 1931, la institución militar llega al poder cuando el dominio de las clases superiores era amenazada por una rebelión campesina. El patrón histórico en los regímenes militares era proteger los intereses económicos de la oligarquía salvadoreña y suprimir movimientos que promovieran reformas sociales tal como la reforma agraria. De acuerdo con Arson (1982:84), "En El Salvador la revolución fue resultado de casi un siglo de control económico de la oligarquía reforzado y facilitado por décadas de gobierno directo por parte de los militares". Por supuesto, caracterizar la institución militar como un simple instrumento de la oligarquía salvadoreña es una simplificación. Alastair White (1983:228) reconoció esa simplificación pero dijo que es una caracterización muy cercana a la relación real entre el gobierno salvadoreño y las élites económicas. 
Por ejemplo, el $1^{\circ}$ de julio de 1976, el Presidente Molina en su discurso al Congreso dijo que nada ni nadie lo iban a detener en su intención de llevar a cabo el proyecto de transformación agraria en El Salvador. Dijo que el ejército apoyaba totalmente su proyecto y el ejército sería el garante de su implementación. Treinta y cinco días después, el Presidente Molina realizó importantes cambios al proyecto de ley del Instituto de Transformación Agraria. Con aquellos cambios, el primer proyecto de transformación agraria era irrelevante. La oligarquía rural se opuso totalmente a la implementación de este proyecto (Castro 1984:237-238).

Como consecuencia, podemos concluir que los regímenes militares durante los años de las décadas de 1960 y 1970 fueron fundamentalmente un instrumento de la oligarquía salvadoreña. Se puede asignar el valor rango de dos a dichos regímenes.

\section{(B) Los regímenes políticos en Honduras}

La administración de Villeda Morales (1957-1963) puede ser caracterizada como un gobierno reformista. Leyes tales como la ley de reforma agraria (1962) y un nuevo código laboral (1959) que reconoció el derecho de libre asociación de los sindicatos, son indicadores del carácter reformista de la administración de Villeda. Sin embargo, su administración estaba bajo un contexto de doble poder: civil y militar (Blanco y Valverde 1987:27).

De hecho, en 1963 el General Oswaldo López Arellano dirigió un golpe de Estado contra el gobierno de Villeda. Este fue un momento crucial en la historia política de Honduras. Desde este momento, la institución armada comenzó a acumular poder político y económico. El ejército se convirtió en la fuerza doméstica más poderosa en la arena política. Blanca y Valverde (1987) argumentan que López Arellano llegó al poder con el apoyo de la oligarquía rural y la burguesía nacional unida a los intereses internacionales en Honduras. López Arellano permaneció en el poder hasta 1971. Como consecuencia de la guerra entre Honduras y El Salvador, fue posible crear un gobiemo de "unidad nacional" (19711972). En este gobierno, las fuerzas conservadoras unidas a la oligarquía rural eran la fuerza dominante (Blanco y Valverde 1987:33).

Las protestas campesinas por la tierra habían aumentado desde 
mediados de la década de 1960 . El proceso de reforma agraria fue prácticamente paralizado. En 1972, hubo una masacre contra los campesinos en Talanquera, departamento de Olancho (Blanco y Valverde 1987:32-33).

López Arellano dirigió un golpe de estado en 1972. Durante 1972-1975 la administración de López Arellano puede caracterizarse como un gobierno reformista en el cual la reforma agraria era una prioridad. Esta administración refleja la correlación de fuerzas entre la institución militar y la oligarquía rural. La institución militar era lo suficientemente fuerte para perseguir intereses de la seguridad del estado a pesar de los intereses económicos de la oligarquía rural. La implementación de la reforma agraria se pensó como una forma de controlar los movimientos políticos de los campesinos.

En 1975, el ejército decidió derrocar el gobierno de López Arellano en favor del Coronel Melgar Castro quien era un conservador. Melgar Castro era sensible a los intereses económicos de la burguesía nacional y los dos partidos tradicionales y otras fuerzas sociales que exigían el regreso a un sistema de elecciones. La transición política a las elecciones fue seguida por la administración del General Policarpio García (1978-1981). Es importante resaltar la poderosa influencia política que los Estados Unidos jugó en este período de transición (Posas 1992:11-19).

Podemos concluir que la fuerza local más poderosa en Honduras desde 1963 es la Fuerza Armada. La élite económica no es lo suficientemente fuerte como para mantener sus intereses como la máxima prioridad de la política pública. Con base en esta suscinta historia política de Honduras y en relación con el tipo de gobierno de El Salvador, un valor rango de uno puede ser asignado al estado hondureño.

\section{Discusión}

Con el propósito de responder a la pregunta de por qué ocurrió una guerra civil en El Salvador mientras que Honduras ha mantenido una relativa estabilidad política, se creó el índice de Inestabilidad Social (IIS). Así: IIS = ID + EE. El índice de desigualdad tiene dos componentes. La desigualdad objetiva que se mide por el ín- 
dice de desigualdad bifurcada y la desigualdad subjetiva que se estima a través de la influencia que la Iglesia Católica ejerció al elevar la conciencia de injusticia social en los años de las décadas de 1960 y 1970.

El índice IIS está basado en la idea de que el problema crucial al responder a la pregunta planteada es cómo el estado y las élites económicas en El Salvador y Honduras respondieron a la desigualdad creciente de distribución de tierras y a niveles más altos de conciencia de injusticia social. El rango para el índice de IIS es de 1 a 6 puntos. De 5 a 6 puntos reflejan una situación de revolución social; de 4 a 4.99 puntos, una situación social próxima a una guerra civil o intentos frecuentes de rebeliones; de 3 a 3.99 puntos, una situación social en la que existe un proceso de rápida formación de movimientos insurreccionales o revolucionarios; y de 1 a 2.99 puntos, una estabilidad política relativa.

Con base en el índice IIS, existen tres combinaciones de condiciones que pueden generar una revolución social en El Salvador y Honduras:

Combinación 1: Un estado autónomo personalista/ una iglesia católica profética/ un índice de desigualdad bifurcada igual al promedio de este índice en América Latina.

Combinación 2: Un estado instrumentalista/ una iglesia católica profética/ un índice de desigualdad bifurcada igual al promedio de este índice en América Latina.

Combinación 3: Un estado autónomo personalista/ una iglesia católica profética.

El siguiente cuadro recoge los principales resultados. 


\section{Cuadro 3}

Indice de Inestabilidad Social (ISS)

en El Salvador y Honduras (1960-1980)

\begin{tabular}{lccccc}
\hline País & Año & $\begin{array}{c}\text { Desigualdad } \\
\text { objetiva }\end{array}$ & $\begin{array}{c}\text { Desigualdad } \\
\text { subjetiva }\end{array}$ & $\begin{array}{c}\text { Estructura } \\
\text { del estado }\end{array}$ & ISP \\
\hline El Salvador & $1960 \mathrm{~s}$ & 1.06 & 1.0 & 2.0 & 4.06 \\
& $1970 \mathrm{~s}$ & 0.93 & 2.0 & 2.0 & 4.93 \\
& & & & & \\
Honduras & $1960 \mathrm{~s}$ & 0.30 & 1.0 & 1.0 & 2.30 \\
& $1970-75$ & 0.50 & 2.0 & 1.0 & 3.50 \\
& $1975-80$ & 0.50 & 0.0 & 1.0 & 1.50 \\
\hline
\end{tabular}

En El Salvador, en los años de la década de 1960, el valor del IIS es 4.06. De acuerdo con la escala del IIS, debería reflejar una situación cercana a una guerra civil o a intentos frecuentes de rebelión. La situación política real en El Salvador en esa época no reflejó ninguna de las dos situaciones que eran esperadas a partir del índice de IIS. Sin embargo, el valor está más cerca de cuatro que de cinco. Un valor entre 3 y 3.99 refleja una situación en la cual existe un proceso de formación rápida de movimientos insurrecionales. En efecto, el inicio de los movimientos revolucionarios que pelearon la guerra civil en los años de la década de los 80 's fue en los últimos años de los sesenta.

A finales de la década de los 70's, el valor de IIS es de 4.93. Este valor de acuerdo con la escala de IIS debe reflejar una situación social cercana a una guerra civil o a intentos frecuentes de rebelión. Esto es exactamente lo que sucedió en El Salvador a finales de dicha década. Una diferencia importante entre las décadas de 1960 y 1970 fue el papel de la iglesia católica en elevar la conciencia. Otra diferencia importante fue la existencia de organizaciones revolucionarias político-militares. Estas organizaciones tenían estrategias específicas para obtener la participación de campesinos, trabajadores y estudiantes quienes participaron en el trabajo pastoral de la iglesia católica en esa época. Además, el estado conservó su estructura instrumentalista. Los altos niveles de represión a finales de la década de 1970 contribuyeron a niveles más altos 
de conciencia de injusticia social.

En Honduras, a finales de la década de 1960, el valor de IIS es de 2.3. Este valor debería reflejar una situación social de estabilidad política relativa. Sin embargo, desde mediados de la década de 1960, las protestas de los campesinos comenzaron a aumentar y el gobierno aumentó los niveles de represión. Es probable que el papel negativo del estado en Honduras, durante este período es subestimado en el índice de IIS. Este papel negativo puede ser explicado por niveles más altos de represión, el estilo dictatorial del régimen de López Arellano, y el hecho que el proceso de Reforma Agraria fue esencialmente bloqueado

Para el período 1970-1975 el valor de IIS es de 3.5. Este valor debería reflejar una situación social en la cual existe un proceso de rápida formación de movimientos insurreccionales. En efecto, en este período la movilización de campesinos fue mayor así como los niveles de represión contra ellos. Este fue el período en el cual dos terribles masacres ocurrieron en el departamento de Olancho. Entre la década de 1960 y el período 1970-1975, las principales diferencias fueron el aumento del rol del sector profético en la Iglesia Católica y una creciente desigualdad en el patrón de distribución de tierras.

Para 1975-1980, el valor de IIS es de 1.5. Este valor debería reflejar una situación de estabilidad política relativa. En efecto, la situación política fue más estable en este período que en el período anterior. Un cambio muy importante en este período ocurrió en el papel de la Iglesia Católica. Fue un cambio de una iglesia profética social activa a una iglesia espiritual pasiva. También, el estado ejerció mayor control sobre las organizaciones populares. Como consecuencia, la movilización de campesinos disminuyó en este período.

El Salvador y Honduras no cumplen ninguna de las tres combinaciones que reflejan una situación de revolución social. Sin embargo, El Salvador tuvo un valor de IIS (4.93) muy cercano la combinación 2. En efecto, un serio intento de revolución social ocurrió en El Salvador a principios de la década de 1980.

Finalmente, las principales diferencias entre Honduras y El Salvador que ayudan a explicar por qué una guerra civil ocurrió en 
El Salvador y no en Honduras son:

* En el período 1970-1975, El Salvador mostró un nivel más alto de desigualdad de la distribución de tierras y un estado instrumentalista que fue incapaz de implementar una reforma agraria. Ambos países tenían un fuerte sector profético en la Iglesia Católica y crecientes protestas populares (especialmente movilización de campesinos).

* En el período 1975-1980, continuaron las dos diferencias anteriores. Pero surgió una tercera diferencia importante. El papel de la Iglesia Católica hondureña cambió dramáticamente de una tendencia profética a una espiritual. La iglesia profética salvadoreña alcanzó su nivel de acción más alto en este período. Al mismo tiempo, el estado salvadoreño fue sustancialmente más represivo contra el movimiento popular. Estos dos últimos factores podrían explicar un nivel más alto de conciencia de injusticia social en El Salvador en este período, contrario a la experiencia en Honduras.

* En El Salvador, la existencia de organizaciones político-militares al comienzo de la década de los 70's jugó un papel importante al ofrecer una alternativa política radical a los campesinos que participaron en las actividades pastorales de la iglesia profética. Este factor estuvo esencialmente ausente en Honduras.

\section{Bibliografía}

Arnson, C. 1982. El Salvador: A Revolution Confronts the United States. Washington D.C.: Institute for Policy Studies.

Blanco, Gustavo and Jaime Valverde. 1987. Honduras: Iglesia y Cambio Social. San José: DEI.

Brocket, Charles D. 1992, "Measuring political violence and Land Inequality in Central America". American Science Review, 86:169176.

Cardenal, Rodolfo. 1980. El Poder Eclesiástico en El Salvador. San Salvador: UCA-Editores. 
Cardenal, Rodolfo, Ignacio Martín-Baró and Jon Sobrino. 1987. La Voz de los sin Voz: La Palabra Viva de Monseñor Romero. (3 ed.) San Salvador: UCA-Editores.

Castro Morán, Mariano. 1984. Función Política del Ejército Salvadoreño en el Presente Siglo. San Salvador: UCA-Editores.

Durham, William H. 1979. Scarcity and Survival in Central America: Ecological Origins of the Soccer Ward. California: Stanford University Press.

González, V. 1978. "La insurrección salvadoreña de 1932 y la gran huelga hondureña de 1954". Revista Mexicana de Sociología, 40:563606.

Henríquez, Pedro. 1988. El Salvador: Iglesia Profética y Cambio Social. San José: DEI.

Midlarsky, Manus I. 1982. "Scarcity and Inequality". Journal of Conflict Resolution, 26:3-38.

Midlarsky, Manus I. 1988. "Rulers and the Ruled: Patterned Inequality and the Onset of Mass Political Violence". "American Political Science Review, 82:491-509.

Midlarsky, Manus I. and Kenneth Roberts. 1985. "Class, state and revolution in Central America: Nicaragua and El Salvador Compared". Journal of Conflict Resolution, 29:63-93.

Montoya, Aquiles. 1991. "El agro salvadoreño: Antes y después de la Reforma Agraria". Cuadernos de Investigación de CENITEC, (junio). San Salvador: Druck.

Moore, Barrington Jr. 1966. Social Origins of Dictatorship and Democracy : Lord and Peasant in the Making of the Modern World. Boston: Beacon Press.

Moore, Barrington jr. 1976. Los Origenes Sociales de la Dictadura y la Democracia. Barcelona: Ed. Península.

Morris, J.A. 1981. "Honduras: An Oasis of Peace?" Caribbean Rev. 10:38-41.

Muller, Edward N. and Mitchell A. Seligson. 1987. "Inequality and Insurgency". American Political Science Review, 81:425-451. 
Muller, Edward N., Mitchell A. Seligson and Hunger-der Fu. 1989. "Land Inequality and Political Violence". American Political Science Review, 83:577-86.

Paige, Jeffrey M. 1987. "Coffee and Politics in Central America" in Richard Tardanico, ed., Crisis in the Caribbean Basin, Bervely Hills, CA: Sage Publications. 141-190.

Pleitez, Rafael A. 1993. "Fourth Essay: The role of elites and revolutions", in the course The Politics of Revolution. University of Pittsburgh.

Posas, Mario. 1987. Breve Historia de las Organizaciones Campesinas en Honduras. Tegucigalpa: Estudio de Artes Gráficas.

Posas, Mario, Julio Navarro, Ramón Oquelí and Leticia Salomón. 1992. Puntos de Vista: Temas Políticos. Tegucigalpa: Centro de Documentación de Honduras.

Prosterman, Roy and Jeffrey M. Reidinger. 1987. Land Reform and Democratic Development. Baltimore: Johns Hopkins University Press.

Reina, J. A. 1981. Honduras: Cambios o Violencia. Tegucigalpa: Artes Gráficas de Centroamérica.

Rosenberg, M. B. 1980. "Are the dominoes falling in Central America?: context, conjuncture and their impacts in Honduras and Costa Rica". Presented at the Illinois conference of Latin Americanist, Northern Illinois University, De Kalb, Ilinois.

Rubén, Raúl. 1991. "El Problema Agrario en El Salvador: Notas sobre una Economía Agraria Polarizada". Cuadernos de Investigación de CENITEC, (abril). San Salvador: Druck.

Rubén, Raúl. 1991. Problema agrario en Honduras. Tegucigalpa: Centro de Documentación de Honduras.

Ruhl, Mark. 1984, "The Influence of Agrarian Structure on Political Stability in Honduras". Journal of Interamerican Studies and Workd Affairs, 18: 33-68.

Sigelman, Lee and Miles Simpson. 1977. "A Cross-National Test of the Linkage Between Economic Inequality and Political Violence". Journal of Conflict Resolution, 21:105-128. 
Skocpol, Theda. 1981. "What Makes Peasants Revolutionary?" Comparative Politics, 14:351-375.

Stokes, W. S. 1966. "Honduras: Problems and Prospects". Current History, 50:22-52.

Tojeira, José María. 1986. Panorama Histórico de la iglesia en Honduras. Tegucigalpa: Centro de Documentación de Honduras.

White, Alastair. 1983. El Salvador. San Salvador: UCA-Editores.

White, Robert. 1977. Structural Factors in Rural Development: The Church and the Peasant in Honduras. Cornell University, Ph. D. Sociology thesis.

Wickham-Crowley, Timothy P. 1992. Guerrillas and Revolution in Latin America: A comparative Study of Insurgents and Regimes since 1956. New Jersey: Princeton University Press.

Wickham-Crowley, Timothy P. 1991. Exploring Revolution: Essays on Latin America Insurgency and Revolutionary Theory. Armonk, N.Y.: M.E. Sharpe.

Notas:

1. Fuentes, Raúl Rubén (1991); Banco Central de Reserva de El Salvador (1984). Conferencias Conmemorativas.

2. La información está basada en el tercer censo nacional agrícola de 1974 en Honduras y de 1971 en El Salvador.

3. La Diocesis de San Salvador incluía varios departamentos en El Salvador tales como San Salvador, La Libertad, Chalatenango, Cuscatlán.

4. Federación Cristiana de Campesinos Salvadoreños (FECCAS). En los años de la década de 1970, esta organización se unió al BPR (Frente Popular Revolucionario). El BPR estaba asociado con las FPL (Fuerzas Populares de Liberación Farabundo Martí) el cual era una organización político militar.

5. Ver Pedro Henríquez (1988), El Salvador: Iglesia Profética y Cambio Social. San José: Editorial Dei. (pp. 205-213). 